PLANT MORPHOLOGY

Vol. 5, No. 2:83-92 (1993)

\title{
Cap-morphogenesis in a Giant Unicellular Alga, Acetabularia caliculus
}

\author{
Kazusachi MINOWA and Ikuko SHIHIRA-ISHIKAWA
}

Department of Biology, Tokyo Gakugei University, Koganei-shi, Tokyo, 184 Japan

(accepted November 1, 1993)

\begin{abstract}
Morphological transition of cap differentiation at the stalk-apex of a giant unicellular alga, Acetabularia caliculus, was observed with a scanning electron microscope. Beginning with a ring-shaped arrangement of primary protuberances, cap-rays were differentiated after the successive development of primary, secondary and tertiary protuberances. The insides of these protuberances were separated into cavities by septa, however these cavities were continuous with each other due to perforation of the septa. Through the pores on the septa, protoplasmic streaming and central vacuole were continuous in all of the cavities and they were also continuous in a whole cell. Based on these structures, the homology and synchrony in the cap-morphogenesis were discussed, concerning turgor pressure.
\end{abstract}

Key words: Acetabularia caliculus, cap-morphogenesis, scanning electron microscopy, turgor pressure.

Acetabularia caliculus Lamouroux in Quoy et Gaimard, a giant unicellular green alga, which has a large central vacuole. The thallus, a single cell, differentiates a cap at the apex of a stalk after repeated differentiation of sterile whorls during stalk elongation.

The cap is an assemblage of about 33 reproductive whorls (cap-rays) (Shihira-Ishikawa 1982). When the stalk normally reaches $30 \mathrm{~mm}$ in length, it terminates its growth and initiates cap formation. The cap-morphogenesis aparently arises from 33 protuberances on the stalk apex, which regularly form a ring. However, these protuberances do not directly develop into cap-rays. The cap-ray is differentiated as the fourth protuberance which remarkably grows. The complicated structure of a group of protuberances seems to play an important role in the evolving of cap-morphogenesis.

The morphological transition during cap differentiation in A. caliculus was briefly described by Arasaki (1942) in a report on its life-cycle. Valet (1968) described the morphogenesis of cap development in A. parvula and A. dentata. We observed cap morphogenesis using a scanning electron microscope. Intracellular structures were 
observed by serial sections using a light microscope. Based on these observations, we discuss the causes of homology and synchrony involved in this morphogenesis.

\section{Material and methods}

\section{Cell culture}

Acetabularia caliculus was harvested in July 1990 on the coast of Notojima Island and was cultured successively in a laboratory. Culture conditions were Müller's synthetic sea water (Müller 1962), $22^{\circ} \mathrm{C}$, illumination with fluorescent lamps(1500 lux), and $L: D=12: 12$.

\section{Electron and light microscopy}

Scanning electron microscopy: Cells at different stages of cap morphogenesis were selected with a dissecting microscope. Whole cells were prefixed by $2 \%$ glutaraldehyde in a $35 \mathrm{mM}$ cacodylate buffer for $2 \mathrm{hrs}$. One hour after the start of fixation, the tips of the cells were cut with scissors and the rest of the cells were removed. $\mathrm{OsO}_{4}(1 \%)$ was applied for post-fixation. The cell pieces were dehydrated stepwise in ethanol. Ethanol was replaced by isoamyl alcohol and the samples were critical-point dried in liquid $\mathrm{CO}_{2}$ (JCPD-5, JEOL). The mounted dry cell pieces were coated with gold-palladium using an ion spatter (JFC-1100, JEOL) and observed with a scanning electron microscope (JEOL F-15).

Light microscopy: Cells were dehydrated through on ethanol series and were then embeded in Spurr's resin (Polyscience). The mounted samples were sectioned with an ultramicrotome (Sorvall Type-MT2) and were stained with toluidine-blue.

Photomicrographs: Fuji Neopan SS 120 film was used for SEM observation and Kodak Tri-X 100 film for light microscopy.

\section{Osmotic pressure}

The vacuolar sap was directly squeezed out onto a small filter paper disk by cutting the stalk. Osmotic pressures of the vacuolar sap and the culture medium were measured with a vapor pressure osmometer (Type 5500, Wescor, USA). The turgor pressure was calculated after van't Hoff's equation by the difference of osmotic pressure between the vacuolar sap and the culture medium.

\section{Results}

Differentiation and development of cap-structure was observed using a scanning electron microscope and cytoplasmic connection in the cap-structure during development was observed with resin-embedded samples using a light microscope.

Primary protuberances appeared at the stalk-apex, which lined up and formed a ring (Fig. 1, 1'). They grew upwards (Fig. 2, 2') and secondary protuberances were formed above each of the primary ones (Fig. $3,3^{\prime}$ ). The secondary protuberances touched with 
adjacent ones and grew upwards (Fig. 4, 4'). The primary protuberances enlarged at the same time. Although the cavities of the primary and secondary protuberances were separated by a septum, the cytoplasm and the central vacuole of both cavities were continuous through a pore on the septum, about $7 \mu \mathrm{m}$ in diameter (Fig. 11). The secondary protuberances synchronously formed two or three tertiary protuberances at their tops (Fig. $5,5^{\prime}$ ). The tertiary protuberances did not grow further and remained as "hairs". A pore bearing septa was formed between the secondary and tertiary protuberances (Fig. 11). At the outer regions of the secondary protuberances, the fourth protuberances were formed (Figs. 6, $6^{\prime}$ and $7,7^{\prime}$ ), which elongated as the vertical enlargement was arrested by adjacent protuberances. During the growth of the fourth protuberances, the secondary protuberances also enlarged outwards (Fig. 8, 8'), but eventually stopped growing. The fourth protuberances grew continuously (Fig. 9, 9') and finally became cap-rays (sporangia) (Fig. 10, 10'). The cap-rays were arranged upwards in the young stage, but gradually changed their angle and were arranged at an angle of 70-80o to the stalk when the cap development was completed. The final size of the cap-ray was $2.0 \mathrm{~mm}$ in length and the diameter of the tip reached $1-1.5 \mathrm{~mm}$ wide. The time elapsed from the initiation of the primary protuberances to the appearence of the fourth protuberances (Fig.1-Fig.6) was about 24 hours with a further requirement of 72 hours before the completion of cap development. The ring-shaped arrangement of the secondary protuberances, including tertiary ones, formed the corona superior, while that of the lower parts of the secondary protuberances formed the corona inferior (Figs. $10 \mathrm{a}$ and $b)$.

The turgor pressures of the cells were measured using a vapor pressure osmometer (Table 1). The average value of turgor pessure before cap formation was $0.64 \mathrm{MPa}(6.3$ atm), while it was $0.52 \mathrm{MPa}(5.1 \mathrm{~atm})$ during cap development. These values showed that the turgor pressure of the cell during cap development was generously the same as it before cap formation. It was concluded, therefore, that the pressure of $0.52 \mathrm{MPa}$ acted upon every developing sites of the protuberances from inside of the cell.

Table 1 Turgor pressure in Acetabularia caliculus before and during cap development

\begin{tabular}{lcc}
\hline \hline & $\begin{array}{c}\text { Osmotic pressure } \\
\mathrm{mmol} / \mathrm{Kg}\end{array}$ & $\begin{array}{c}\text { Turgor pressure } \\
\mathrm{MPa}\end{array}$ \\
\hline Before cap development & 1266 & 0.64 \\
During cap development & 1211 & 0.52 \\
culture medium & 984 & - \\
\hline \hline
\end{tabular}




\section{Discussion}

In all of the species in Acetabularia, caps do not originate from simple enlargement of the stalk-apex. A ring shaped arrangement of the protuberances is formed synchronously on the stalk apex and the successive protrusions occur on the first protuberances (Fig.1-9). In A. caliculus, the cap-ray is the fourth protuberance which has specifically grown, while other protuberances, primary, secondary and tertiary ones, remain at the joint of the cap-ray on the stalk apex. The structures, number, shape and size of these protuberances are keys for systematic classification of Acetabularia (SolmsLaubach 1895). These protuberaces, except the fourth ones, are arranged circularly on the stalk-apex, forming species-specific corona (See Fig. 10). Berger and Kaever (1992) clearly showed the species-specific views of corona with scanning electron micrographs.

A cap is a complex consisting of a number of strictly identical structures, however microtubule organization seems not to contribute to the cap morphogenesis. The immunofluorescence observation revealed that the microtubules emerged on the surface of the secondary nuclei in the complete cap-rays (Shihira-Ishikawa 1989), but were not observed throughout the cap development (Shihira-Ishikawa, unpub. data). Numerous secondary nuclei are transported from the rhizoid to the cap after the completion of cap formation (Shihira-Ishikawa 1984) and numerous gametangium are formed in the capray. Although the microtubules in an Acetabularia cell are involved in the gametangium formation (Menzel 1987, Shihira-Ishikawa 1989), as they are involved in nuclear divisions, they are not involved in cap morphogenesis. Why does a cell form identically shaped protuberances without involvement of microtubule organization and develop them synchronously? Why do these protuberances finally form a geometrically regulated structure in a cap? We found temporary answers to these questions based on the above observations. The answers are as follows: (1) Because of a continuity of a central vacuole, turgor pressure expands plasma membrane equally at each of the developing sites of the protuberances where the cell wall is still incomplete, (2) protoplasmic streaming supplies materials and energy evenly to all developing sites, because the streaming is continuous via a small pores on each septum, and (3) adjacent protuberances touched each other supressing further lateral enlargement in each protuberance.

Another question concerns why each cap-ray contains the secondary nuclei in the same number, without any nuclear division in the cap-ray? It may be that the identically shaped cavities at the joint of each cap-ray fulfill the role of distributing protoplasm equally; the numerous secondary nuclei are assembled at the stalk-apex during transportation to the cap-rays, and protoplasm including secondary nuclei are divided evenly into each cavities, because these cavities are homologous. Thus the complicated structure of a cap may play an important role for the smooth evolvement of the life-cycle of this organism, though these protuberances are formed as modified sterile whorls. 


\section{Acknowledgement}

The authors express their thanks to Dr. M. Kikuyama, The University of the Air, for his kind help in measuring turgor pressure of Acetabularia cells.

\section{References}

Arasaki, S. 1942. On the life-history of Acetabularia calyculus Quoy et Gaimard. Bot. Mag. Tokyo 56:383-390.

Berger, S. and Kaever, M.J. 1992. Dasycladales. Geprg Thieme Verlag, Stuttgart, New York.

Menzel, D. 1986. Visualization on cytoskeletal change throughout the life cycle in Acetabularia. Protoplasma 134:30-42.

Müller, M. 1962. Über Jahres- und Lunarperiodische Erscheinungen bei einigen Braunalgen. Bot. Mar. 4:140-155.

Shihira-Ishikawa, I., Yano, D.M.Y. and Imahori, K. 1982. An interspecific graft between two Japanese species of Acetabularia. Jpn. J. Phycol. (Sorui) 30:1-7.

Shihira-Ishikawa, I. and Kuroiwa, T. 1984. Morphological transition of the nucleus duing the whole life cycle of Acetabularia calyculus Quoy et Gaimard. Jpn. J. Phycol. (Sorui) 32:147-157.

Shihira-Ishikawa, I. 1989. Spatial and temporal organization of microtubules in the cyst formation of Acetabularia calyculus Quoy et Gaimard: Visual observation of the segregation of cytoplasmic units. Kor. J. Phycol. 4: 87-96.

Solm-Laubach, H. 1895. Monograph of the Acetabulariae. Trans. Linn. Soc. Bot. London II 5:1-39.

Valet, G. 1968. Contribution a l'etude des Dasycladales 1. Morphogenese. Nov. Hedw. 16:22-84. 
Figs. 1-9. Scanning electron microscope observation of the cap development. 1'-9'. Cross sectioned views of protuberances by drawings. The number of drawings corresponds to the number of scanning electron micrographs. 1,1'. Primary protuberances (I) appeared at the stalk-apex in a ring shape. 2,2'. Developement of the primary protuberances. $3,3^{\prime}$. Differentiation of secondary protuberances (II). $4,4^{\prime}$. Upward growth of the secondary protuberances. 5,5'. Differentiation of tertiary protuberances (III). 6,6'. Appearance of fourth protuberances (IV) at the vertical sites of the secondary protuberances. $7,7^{\prime}$. Development of the fourth protuberances. $8,8^{\prime}$. Outward growth of the secondary protuberances. 9,9'. Upward growth of the fourth protuberances. a. Tangential view. b. top view. Bars: $50 \mu \mathrm{m}$ Bars: $1 \mathrm{~cm}$. Figs. 1-6: 24 hours. Figs. 6-8: 36-48 hours. Figs. 8-9: 36-48 hours.

Fig. 10. Fully developed caps observed with light microscope. a. Top view. Arrow indicates corona superior. b. back view.Arrow indicates corona inferior. c. Side view. st, stalk. sw, sterile whorl. Arrow indicates corona inferior. 10'. Cross sectioned view of protuberance of fully developed cap by drawing.

Bars: $1 \mathrm{~cm}$. Fig. 10: 36-48 hours.

Fig. 11. Serial sections (a-f) of a protuberance observed with a light microscope. The sample is at the stage of Fig. 8. Arrows indicate the pore on the septum between the primary and secondary cavities. Arrowhead: Septum with a pore between the secondary and tertiary cavities . Bar: $10 \mu \mathrm{m}$ 

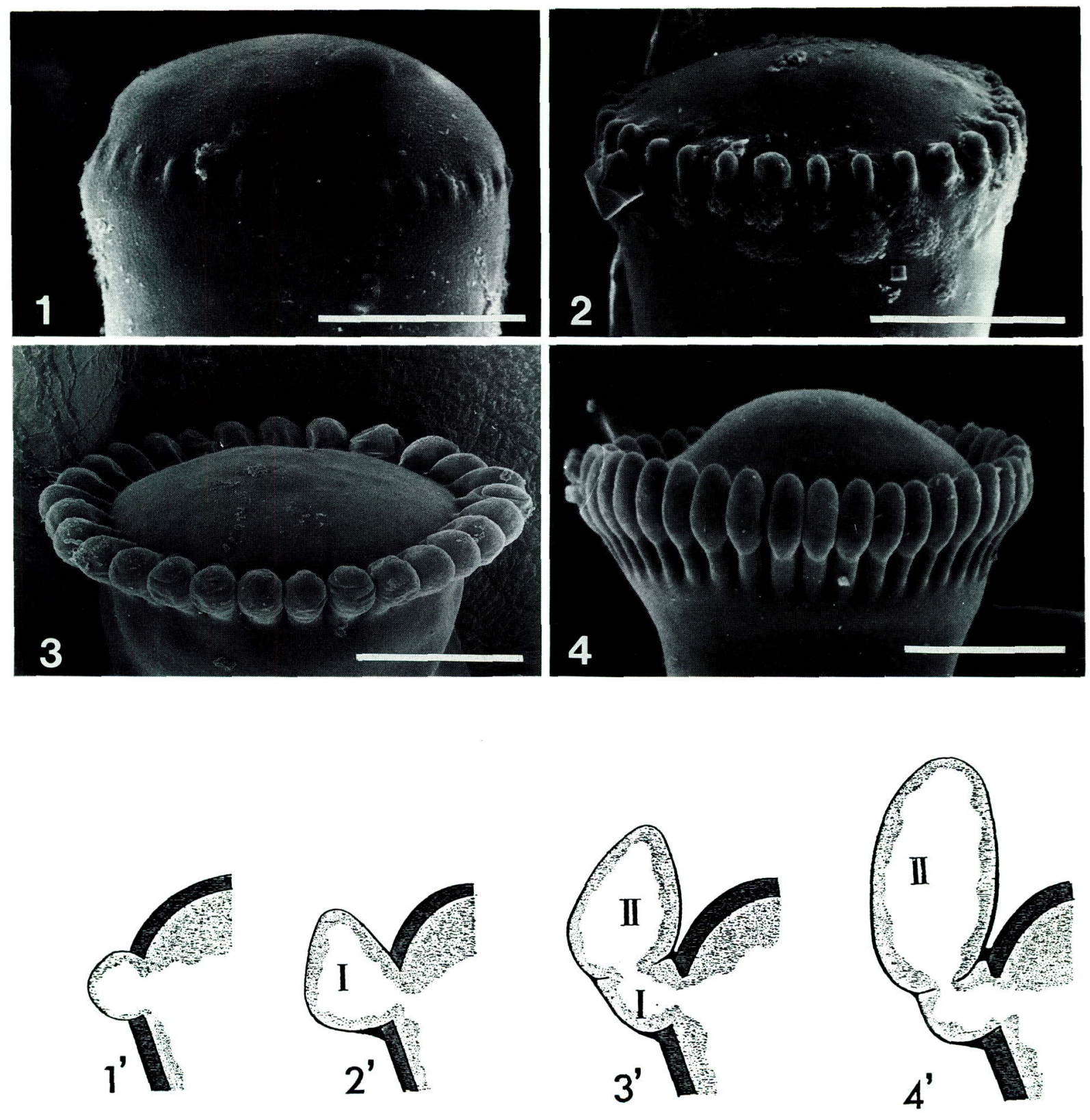

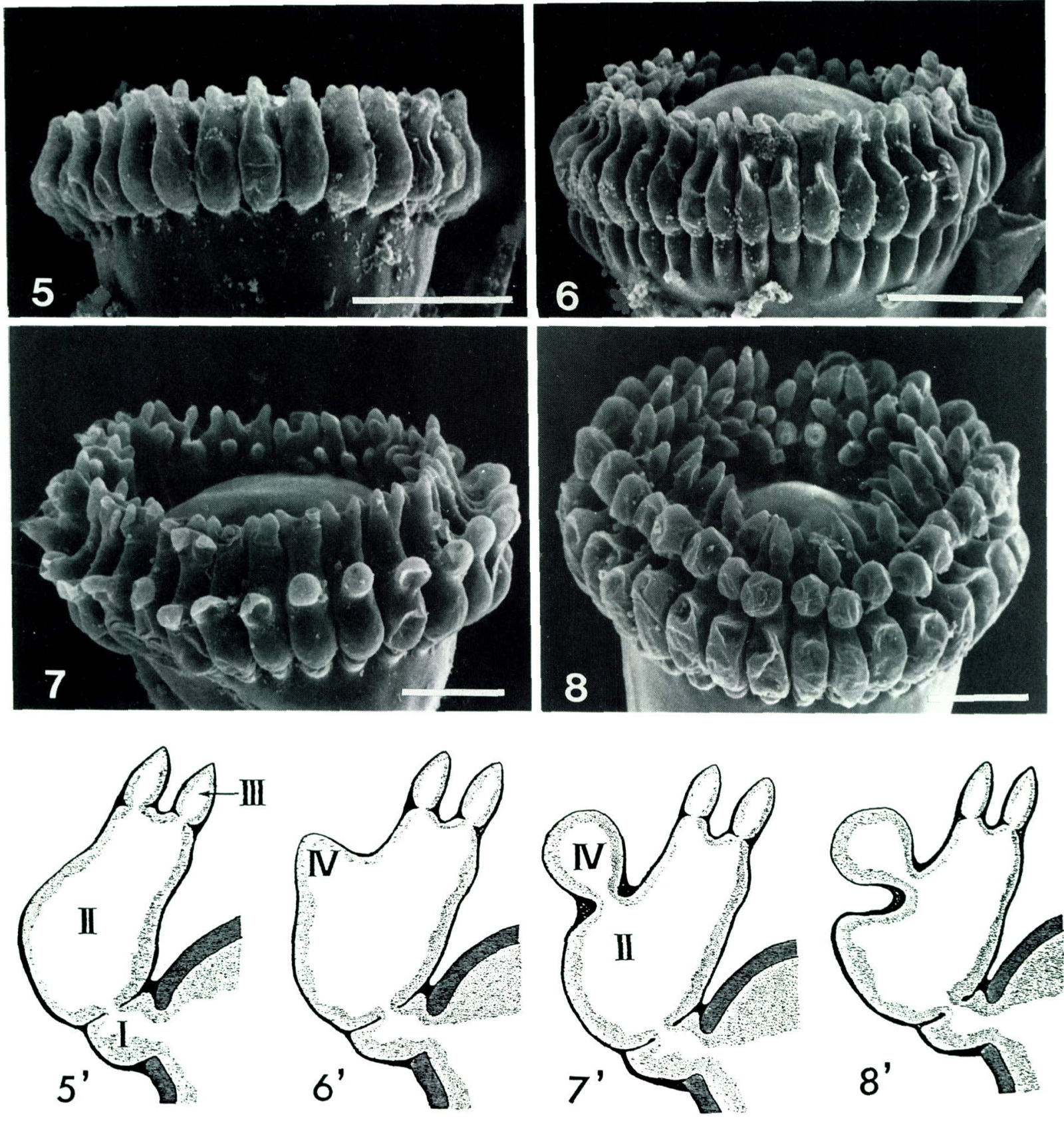

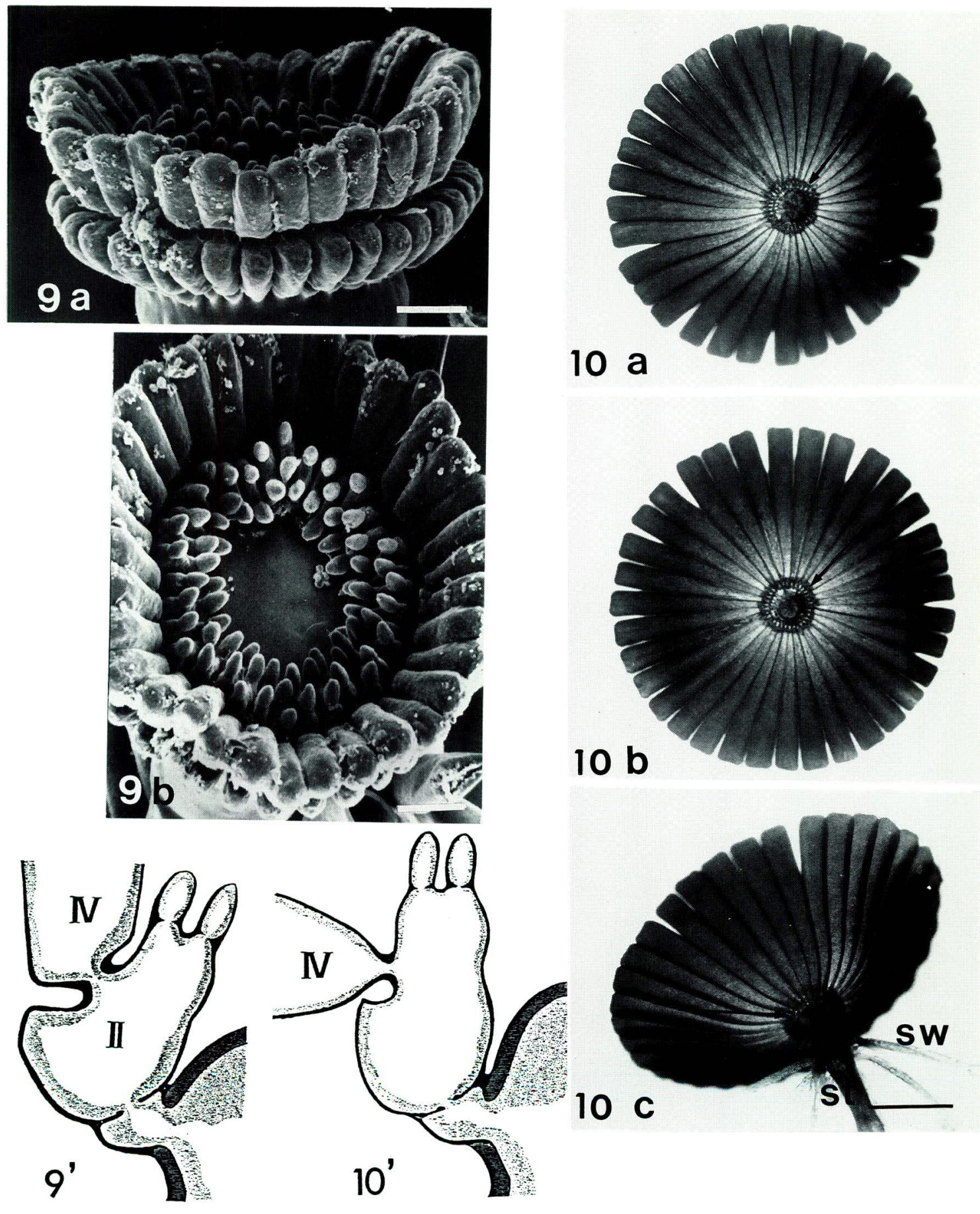


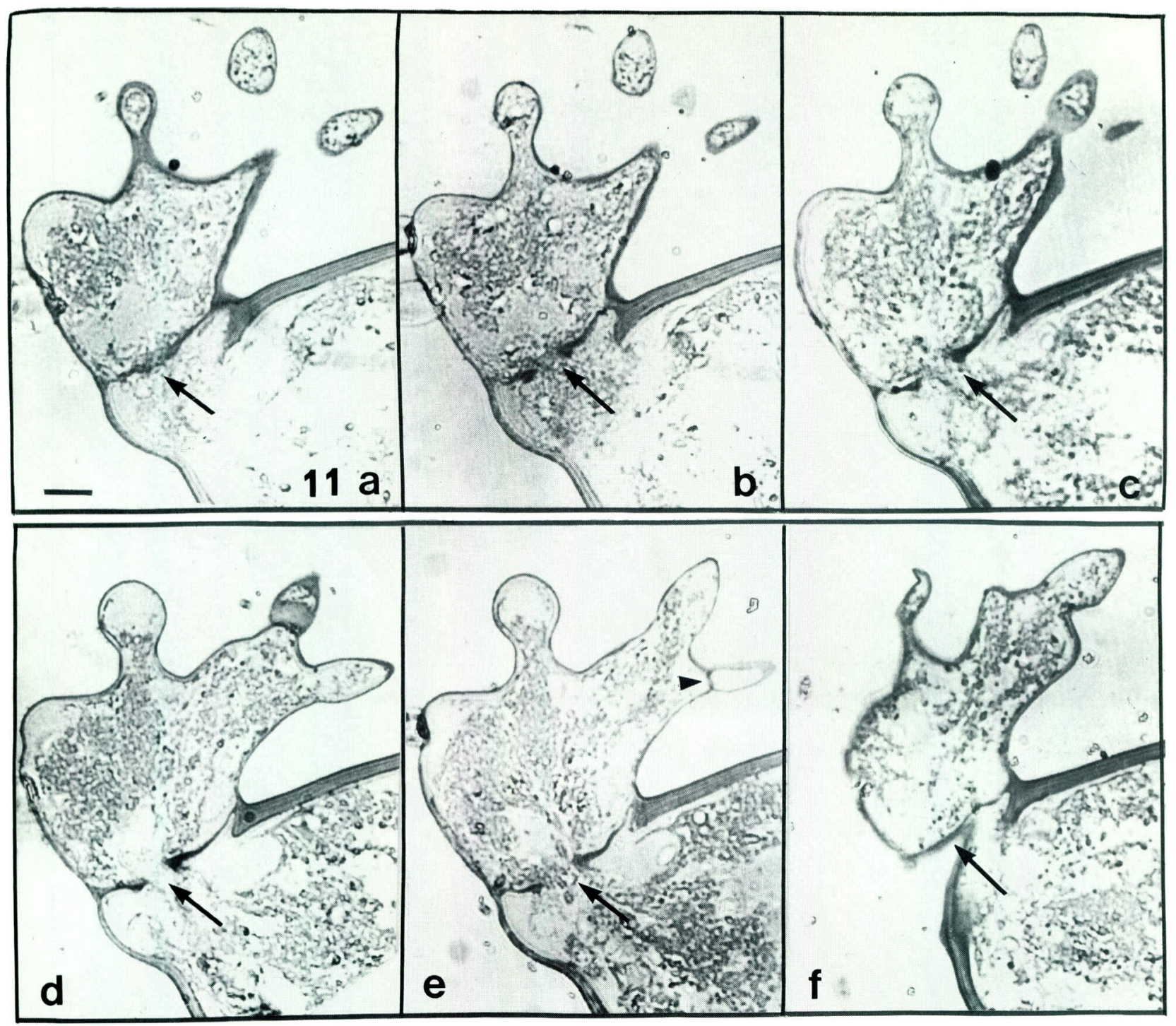

